\title{
CTiBS and Clinical Social Work: Telebehavioral Health Competencies for LCSWs in the Age of COVID-19
}

\author{
Crystal A. Merrill 1 (D) Marlene M. Maheu ${ }^{2} \cdot$ Kenneth P. Drude ${ }^{3} \cdot$ Laura W. Groshong $^{4} \cdot$ Mirean Coleman $^{5}$. \\ Donald M. Hilty ${ }^{6}$
}

Accepted: 3 December 2021 / Published online: 13 January 2022

(c) The Author(s), under exclusive licence to Springer Science+Business Media, LLC, part of Springer Nature 2021

\begin{abstract}
Licensed Clinical Social Workers (LCSWs) have been integrating technology into psychotherapy practice for at least two decades, but the COVID-19 pandemic dramatically shifted the primary method of service delivery for diagnostic assessment and therapy to telebehavioral health. By developing telebehavioral health competencies, the 250,000+LCSWs in the US can ensure and enhance the quality of care both during and after the COVID public health emergency (PHE). This article applies an evidence- and consensus-based, interprofessional telebehavioral health (TBH) competency framework to the field of social work. This framework was developed by the Coalition for Technology in Behavioral Science (CTiBS), initially published in 2017. It has seven competency domains: (1) clinical evaluation and care; (2) virtual environment and telepresence; (3) technology; (4) legal and regulatory issues; (5) evidence-based and ethical practice (comprised of Standards and Guidelines and Social Media); (6) mobile health and apps; and (7) telepractice development. The framework outlines three competency levels (novice, proficient, and authority) covering 49 specific objectives and 146 measurable competencies or practices. The TBH competencies support existing in-person clinical practices and are intended for trainees and practitioners who are implementing TBH in practice. This competency framework can also be used to integrate clinical social work professional development, research, and training. Additionally, considerations for other behavioral health professions regarding licensure, certification, and policy may apply to clinical social work. Future research is needed on implementation and evaluation of the competencies.
\end{abstract}

Keywords Telebehavioral health $\cdot$ Telemental health $\cdot$ Teletherapy $\cdot$ eHealth $\cdot$ e-therapy $\cdot$ Competencies $\cdot$ Competency $\cdot$ Framework $\cdot$ Interprofessional $\cdot$ Interdisciplinary

Crystal A. Merrill

crystal.merrill@ capella.edu

1 School of Public Service \& Education, Capella University, Minneapolis, MN 55402, USA

2 Telebehavioral Health Institute, San Diego, CA, USA

3 Independent Practice, Dayton, OH, USA

4 Clinical Social Work Association, Seattle, WA, USA

5 National Association of Social Workers, Washington, DC, USA

6 Northern California Veterans Affairs Health Care System, Mather, CA, USA

\section{Introduction}

Thrust into telehealth practice because of the urgency imposed by the COVID-19 pandemic, many Licensed Clinical Social Workers (LCSWs) are regaining their footing from the forced adoption of telehealth to maintain continuity of care with clients/patients. However, many LCSWs may still be unaware of the decades of research that has supported the implementation of telebehavioral health (TBH) (Maheu et al., 2005) and of the more recent research on feasibility, clinical outcomes, and effective service delivery models (Hilty et al., 2018). Likewise, many practitioners may not yet have had the opportunity to familiarize themselves with successful telehealth practice or experience formal continuing education, despite the readily available TBH training organizations available online. 
The COVID-19 pandemic propelled telehealth into millions of U.S. homes and workplaces, thus sparking consumer, client/patient, and organizational interest. While TBH has provided continuity of care for millions impacted by the global pandemic, challenges remain. On the one hand, people have experienced the many conveniences of videoconferencing and have learned many basic functions, such as how to open a videoconferencing window, mute themselves, share their screens, and show their clinicians around their homes and other aspects of their lives outside of the clinical office. On the other hand, a variety of factors create clinical, professional, regulatory, and legal challenges that will continue to be difficult to navigate (for example, legal and ethical considerations in interstate practice) (Wodarski \& Frimpong, 2013). However, it is reasonable to believe that there is no going back and that telehealth will likely remain part of healthcare in the form of a hybrid model that includes both in-person and online services. This article is written to outline some of the key issues in TBH practice, provide relevant resources, and support LCSWs to practice ethically and effectively using TBH.

In the behavioral health community, telehealth has historically received considerable attention-mostly related to video-but extending to additional technologies such as telephone, remote patient monitoring, and electronic health records. Populations that can be served include the entire range of age groups through the lifespan-from infants, children, adolescents, families, and the aging population-in a variety of settings, from rural and frontier to urban areas (Hilty et al., 2018, 2020). For example, the American Telemedicine Association (ATA) published child and adolescent guidelines (2017) to include factors previously outlined in adult guidelines (ATA, 2009; ATA, 2013). Technologies covered included apps, asynchronous services, email, e-consultation, monitoring, social media, text, and wearables as adjuncts to in-person care or video. The most recent audit by Centers for Medicare and Medicaid Services' (2018) revealed how forward-thinking these guidelines are. One of the outcomes of the audit indicated that $85 \%$ of all telehealth services reimbursed were behavioral in nature (Centers for Medicare \& Medicaid Services, 2018).

LCSWs have long acknowledged the value that TBH brings to their practices and their clients/patients (McCarty \& Clancy, 2002; Perron et al., 2010; Wodarski \& Frimpong, 2015). As a result, aware of the mounting need for guidance for social workers in the use of rapidly proliferating technology, the National Association of Social Workers (NASW), the Clinical Social Work Association (CSWA), the Council on Social Work Education (CSWE), and the Association of Social Work Boards (ASWB) (2017), developed and published the Standards for Technology in Social Work Practice (Standards for Technology). These standards were then integrated into the Codes of Ethics for NASW in 2017 and the
CSWA in 2018. The Standards for Technology provide the foundation for ethically and effectively using technology in social work practice and cover a broad range of considerations to guide social workers as they provide information to the public, design and deliver services, gather, manage, and store information, and facilitate social work education and supervision (NASW, 2017). With these Standards, social workers moved even further forward in utilizing technology to fulfill one of the tenets of the profession- to meet people where they are!

This article provides a steppingstone for LCSWs, trainees, educators, and leaders in contextualizing the development of TBH standards and guidelines and enhancing quality of care through purposeful teaching and building of skills and competencies. While the primary focus of many articles related to TBH is related to ethical, legal, and policy issues (Barsky, 2017), this article focuses on a competency framework, including a sampling of objectives and behaviors that demonstrate competent TBH clinical practice.

\section{Competency-Based Education and the CTiBS Competency Framework}

In behavioral health, a competency-a measurable human capability required for effective performance-may include individual and aggregate components of skill, knowledge, attitudes, or personal qualities. The latter category includes attitudes, but may have emotional, personality, value, or other components. These elements affect a range of personal behaviors such as how a person conducts themself, habits kept, ways of interacting, and manners (Marrelli et al., 2005) to broader, more culturally determined behaviors. The CSWE 2015 Educational Policies and Standards (EPAS) states that social work competence is the "ability to integrate and apply social work knowledge, values, and skills to practice situations in a purposeful, intentional, and professional manner to promote human and community well-being" ( $p$. 6). Clinical social work practice takes this definition further by applying it to the practice of psychotherapy and other forms of behavioral health (CSWA Code of Ethics, 2018).

In addition to general skill acquisition, competency-based education focuses on clinical skill development in providing psychotherapy (Iobst et al., 2010; Northey \& Gehart, 2019). Clinical care and training in psychotherapy is a crucial part of competency training (i.e., online, e- or otherwise framed) (Nelson \& Sharp, 2016; Pickens et al., 2019). In a recent study, however, Cwikel and Friedmann (2019) found that clinical social workers, at least prior to the pandemic, were considered "late adopters" of information and communication technology. One of the reasons for this late adoption may be related to the identified barrier of "need for quality training by an experienced practitioner..." The study concluded that "training should focus on developing e-therapy 
skills by emphasizing responsibilities such as for data security, benefits, and barriers" in using information and communication technology.

It is clear that having proficiency in clinical social work is not the same as having proficiency in TBH clinical social work. For example, making a phone call from an analog dial-up telephone involves a different skill set than making a call from a smartphone. It is not uncommon for professionals-in-training to have advanced-level technology-related knowledge and skills that surpass the technology knowledge of their clinical instructors and mentors. Thus, new technology-specific skills must be learned by LCSWs. Levin et al. (2018) assert training in technology is critical for social work educators to develop comfort and proficiency. Proficiency (competence) must, however, be assessed. It is at this point the Coalition for Technology in Behavioral Science (CTiBS) competency framework (Maheu et al., 2018) intersects with and can inform competent TBH clinical social work practice.

The CTiBS competency framework (Maheu et al., 2018) is comprised of 146 competencies identified as relevant to the practice of telebehavioral health, the term used by the Substance Abuse and Mental Health Services Administration (SAMHSA) as the digital delivery of substance use and mental health services. It is an evidence- and consensusbased, interprofessional TBH competency framework forged by input from practitioners in the fields of addiction/substance use, counseling, couples/marriage and family therapy, psychiatry, psychology, clinical social work, and other behavioral health disciplines.

CTiBS identified seven competency domains to give practitioners a firm footing in the decades of research and practice that form the foundation for TBH practice. These competencies are based on a detailed review of the scientific literature, technological advances, and day-to-day clinical practice. The seven competency domains are (1) clinical evaluation and care, with three subdomains addressing evaluation and treatment, cultural sensitivity and diversity, and documentation and administrative procedures; (2) virtual environment and telepresence; (3) technology; (4) legal and regulatory issues; (5) evidence-based and ethical practice, with two subdomains addressing Standards and Guidelines and Social Media; (6) mobile health and apps; and (7) telepractice development.

Traditional competencies are organized and based on a developmental progression from training to clinical practice (Dreyfus \& Dreyfus, 1980). Similarly, the CTiBS framework uses three levels of proficiency: novice, proficient, and authority. This framework is framed with the understanding that requisite in-person clinical expertise has been developed as a minimum baseline. Generally speaking, a clinician has to master all (or most of) the previous level's skills (i.e., novice) to advance to the next level (i.e., proficient). A summary of novice-level skills indicates that the novice can identify, describe, educate, and adhere to fundamental clinical issues/ practices and operate technology [at a beginning level of clinical practice].

In addition to novice-level TBH skills, the proficient-level practitioner can also anticipate client/patient matters, implement TBH advances, and document any adjustments made to approximate in-person care while following all relevant laws, regulations, ethical codes, and administrative policies and procedures. In some cases, the proficient-level practitioner must market TBH practice through the Internet. The tasks can be daunting without specific training. This midlevel group of telepractitioners, those who have developed TBH competencies at the proficient level, also includes supervisors who help novices learn TBH best practices.

The authority-level TBH practitioner may function in advanced clinical, leadership, and consultant roles or be a scholar, researcher, policymaker, or trainer. The CTiBS competencies, then, follow an ever-developing progression and acquisition of TBH knowledge and skills from the novice through to the authority practitioner and provide a lens with which to assess TBH competencies at each respective level. Since there is not yet a standardized method for assessing TBH competency for LCSWs, the CTiBS competencies can serve as a guide for self-assessment in TBH clinical social work practice.

\section{Telebehavioral Health Competencies and Self-Assessment}

Competencies are nothing new to clinical social work. Clinical Social Work practitioners have worked for several decades to identify and assess practice competencies, primarily during graduate training. The CSWE Educational Practices and Standards (EPAS) recognizes a holistic view of competence; that is, that demonstration of competence is informed by "knowledge, values, skills, and cognitive and affective processes that include the social worker's critical thinking, affective reactions, and exercise of judgment in regard to unique practice situations" (Council on Social Work Education, 2018, p. 6). The Standards for Technology (2017), Standard 2.06, clearly guides all clinical social workers who use technology to "obtain and maintain the knowledge and skills required to do so in a safe, competent, and ethical manner" (p. 16).

Especially now that so many clinical social workers are already practicing telehealth, many without formally structured training to identify learning gaps, it is important for LCSWs to conduct a systematic self-assessment of their TBH knowledge and skills. The goal of such assessment would be to formulate a professional development plan to develop the necessary competencies for performing 
telehealth services. The CTiBS TBH competencies framework (Maheu et al., 2018) provides a comprehensive structure for such an assessment. Suggested approaches and ideas about conducting such professional self-assessments and developing self-directed educational and training plans in response to self-assessment are described by Drude et al. (2019), members of the CTiBS development team.

For the inquisitive and dedicated LCSW, numerous TBH resources are readily available, including professional publications in journals and books, individual webinars, and organized certification programs. Consulting with more experienced telehealth practitioners, including those in other behavioral health professions, may be an additional option to consider within the self-assessment process. When a selfassessment has been completed, LCSWs will need to tailor educational systems, training resources, and clinical TBH approaches to acquire sufficient skills and competencies for ethical and effective practice in each aspect of clinical practice.

The next sections of this article present brief overviews and discussions of two of the three subdomains of the Clinical Evaluation and Care domain, Evaluation and Treatment and Documentation and Administrative Procedures, as well as the Legal \& Regulatory Issues competency domain.

\section{CTiBS Competency Framework: Clinical Evaluation and Care Domain}

The definition of telehealth has rapidly shifted and expanded over the previous two decades. Telehealth, in general, refers to health services delivered by health care professionals using a variety of communication technologies. Telehealth includes clinician communications with clients/patients, other professionals, residents, interns, students, and administrators, as well as both professional and family caregivers. Telehealth generally is seen as belonging to one of two broad categories: Synchronous, real-time videoconferencing, telephone-based, or other communications or Asynchronous, communication not in real-time that is responsive to past communications.

In a general sense, the delivery and administration of distance health services all fall within the broad telehealth categories. As technology continues to develop, the many uses of telehealth services have also evolved and expanded. These services include clinically related matters such as consultation, assessment, treatment, patient monitoring, and education and/or training for clients/patients, any relevant caregivers, and other treatment professionals. Telehealth also includes healthcare administration, billing, and health information exchanges. Competencies related to clinical evaluation and care, including administration as part of clinical care, are critical for LCSWs to develop. Since the space for this article is not sufficient to discuss all aspects of clinical evaluation and care, the following presents several foundational considerations for LCSWs engaging in TBH clinical practice.

\section{Evaluation and Treatment Subdomain}

The CTiBS Telebehavioral Health Competency Framework includes Evaluation and Treatment, one of the subdomains of the CTiBS Clinical Evaluation and Care domain. When providing clinical care, the LCSW must determine how to best use the "therapeutic hour," whether it is in-person, via videoconferencing, or on the telephone. Some basic questions related to telehealth care and education that LCSWs should ask include:

- What is the best way to align a technology to meet the specific needs of any given client/patient?

- How can clients/patients and practitioners be empowered to reflect on and weigh the pros and cons of available options to learn new behaviors and evaluate outcomes?

- How do LCSWs ensure clients/patients use technology wisely to prevent and/or avoid potentially negative outcomes from the use of technology?

- How can LCSWs providing TBH services find and access emergency services that are close to their client/patient?

- How can TBH clinicians encourage trainees and other practitioners to learn best practices for TBH care delivery and develop skills using TBH?

These are just a few of the questions that competent TBH practitioners must address. There is another key aspect that must also be addressed-that of documentation and administration.

\section{Documentation and Administrative Procedures Subdomain}

Also addressed within the CTiBS framework, the subdomain, Documentation and Administrative Procedures, includes TBH competencies related to initial and ongoing informed consent; intake notes, diagnostic assessment and initial evaluation; treatment plan, progress note(s); release(s) of information; and termination/discharge planning and documentation. Other documents may include business and financial documents such as Notice of Privacy Practices (NPP), Business Associate Agreement (BAA), Release of Information (ROI), Informed Consent, TBH training certifications, continuing/professional education course completion certificates, and more. This subdomain also includes the importance of adhering to professional, agency, and other organizational policies/procedures. Thus, it is essential for 
all LCSWs to be well-versed in the processes and procedures for TBH clinical practice.

As with all clinical services, proper documentation for TBH visits remains critical. Many telehealth technologies link or embed the electronic health record (EHR) for streamlined documentation. TBH documentation may need to include, at a minimum:

- Details of the informed consent discussion specific to TBH, including notation of issues clarified and questions answered, along with a signed TBH-specific informed consent addendum to be added to a practice's regular informed consent document.

- A statement outlining the fact that the service was provided using telehealth.

- A description of the type(s) of technology used, whether it is HIPAA-compliant, and that a Business Associate Agreement (BAA) was obtained.

- The locations of both the clinician and the client/patient.

- The start and ending times for each session to document session length requirements for payor and/or state(s) involved.

- A notation of any unexpected events such as connectivity interruptions or guests and/or intruders who entered the session uninvited.

As with in-person clinical services, all communication with patients through TBH should be encrypted to HIPAA standards and documented in the patient record. This includes text messages, chats, and other forms of electronic communication. Of course, administrative aspects for TBH clinical services must also include considerations for reimbursement for services, including changes related to COVID-19 factors. This is also addressed within the Documentation and Administrative Procedures subdomain.

Billing for TBH services requires the use of Current Procedural Terminology (CPT) codes, just as for in-person clinical services. Service codes for telehealth have increased in number and variety for more than two decades, with new codes being approved by the Centers for Medicare and Medicaid Services (CMS) and posted in the Federal Register annually. For COVID-19, that list of CPT codes was expanded. Due to limited space and given the rapidly changing fluctuations in reimbursement rates and regulatory code related to telehealth, resource links are provided in Table 1 for information regarding TBH services, reimbursement, and CPT Codes as of the date of this writing.

Thus far, two subdomains of the CTiBS Clinical Evaluation and Care domain have been discussed, along with relevant questions and practices for LCSWs to consider. This information has direct implications for ethical and effective client/patient care as well as legal implications for the LCSW. With that knowledge, the following section provides an introduction to some legal and regulatory aspects related to $\mathrm{TBH}$ practice.

\section{CTiBS Competency Framework: Legal and Regulatory Issues Domain}

A third example of the CTiBS competency framework is the Legal \& Regulatory Issues domain. This domain focuses on ensuring that TBH laws and regulations are followed and that they are implemented in practice and supervision, as they would be in an in-person context. This domain relates to HIPAA guidelines, privacy, business associate agreements (BAA), and interjurisdictional practice and portability.

\section{Privacy}

While clinical social workers will be familiar with the Health Insurance Portability and Accountability Act (HIPAA) and HIPAA-compliant technology in traditional face-to-face practice, HIPAA regulations must also be observed in TBH practice. In the early weeks of the COVID-19 pandemic, the Office for Civil Rights (OCR) (2020), the federal department charged with enforcing HIPAA, published the Notification of Enforcement Discretion for Telehealth Remote Communications During the COVID-19 Nationwide Public Health Emergency. While maintaining that all HIPAA laws are still in full effect, the OCR announced that it would exercise "enforcement discretion" of HIPAA. Professionals, including LCSWs, could use technology that did not meet prior standards. These included platforms such as Skype, Facetime, and other "non-public-facing" technologies. Conditions for this discretion included the practitioner's need to make "good faith" efforts to protect the client's/patient's privacy as much as possible and explain the risks to the client/

Table 1 Resource list

\begin{tabular}{ll}
\hline Name of Resource & Resource URL \\
\hline Telehealth Policy and Reimbursement by State & https://www.cchpca.org/telehealth-policy/current-state-laws-and-reimbursement-policies\# \\
Telehealth Codes: & https://www.cms.gov/Medicare/Medicare-General-Information/Telehealth/Telehealth-Codes \\
Federally Qualified Health Centers (FQHCs) & https://www.hrsa.gov/opa/eligibility-and-registration/health-centers/fqhc/index.html \\
Rural Health Clinics (RHCs): & https://www.ruralhealthinfo.org/topics/rural-health-clinics \\
\hline
\end{tabular}


patient prior to using non-compliant software. The OCR also issued guidance encouraging professionals, including LCSWs, to use HIPAA-compliant software, including endto-end encryption-secure communication that prevents third-party access - as much as possible. Even with HIPAA enforcement discretion, LCSWs must still comply with the guidelines and regulations set forth by HIPAA to effectively safeguard a client's/patient's Protected Health Information (PHI).

\section{Business Associate Agreements}

In addition to privacy considerations, LCSWs are also required to obtain a Business Associate Agreement from all vendors that have access to electronically protected health information (ePHI), including video, audio, text messaging, cloud storage, apps, practice management software, or remote patient monitoring (this list is not all-inclusive). BAAs are between a practitioner and another party and provide the clinician a written assurance that the third party is aware of and compliant with the LCSW's Confidentiality Policies and Procedures. The BAA, in essence, is the vendor's legal declaration that they will protect all data associated with a client/patient event according to the LCSW's HIPAA policies and procedures. These privacy-related aspects of TBH practice are presented as a brief introduction. LCSWs who would like to learn more about HIPAA requirements should consider consulting a healthcare compliance attorney, their compliance officer, the Centers for Medicare and Medicaid Services, or the U.S. Department of Health and Human Services for more information.

In addition to privacy factors, there are numerous other legal and regulatory aspects that LCSWs must consider. Some of these considerations have to do with interjurisdictional practice, licensure portability, and clinical social work practice.

\section{Interjurisdictional Practice and Licensure Portability}

While TBH practice is legal in all 50 states, the laws and regulations for TBH practice by clinical social workers vary from state to state. Generally, LCSWs must hold a license in the same state in which the client/patient is located when services occur. During the COVID pandemic, some states temporarily approved interjurisdictional practice-but no blanket rule has yet been applied nationally. If an LCSW's client/patient is not in the state that the LCSW is licensed, the LCSW must carefully check the laws and regulations in the state where their client/patient is located to see if they can legally continue to provide services to them (Camper \& Felton, 2020). For the most current and pending general telehealth state laws, check resources provided by the Center for Connected Health Policy (https://www.cchpca.org/) or the Association of Social Work Boards (https://www.aswb.org).

While not exhaustive, the following checklist may be helpful for LCSWs to consider prior to initiating or maintaining TBH services in jurisdictions other than where the LCSW is licensed:

- Research the definition of "practice" in each state of service delivery, as such definitions can differ widely from state to state.

- Confirm valid licensure and seek licensure or official registration for all clinicians who serve clients/patients in other states, provinces, or countries.

- Consider legal counsel to prepare documentation to adapt to interstate legal requirements.

- Only use billing practices that are in accord with the laws of the payor in each state, as these may differ from state to state.

- Verify professional liability coverage that includes telehealth with all involved carriers prior to delivering telehealth services.

Each of the components of the checklist is to prompt LCSWs in thinking about some of the aspects of legal and regulatory components of TBH clinical practice. There are also similar considerations for social workers receiving supervision. As with licensure portability, there are many professional licensing boards whose laws and regulations vary between professions - sometimes even within the same state. It is, therefore, incumbent on the TBH supervisor to be aware of all relevant TBH laws and regulations (jurisdictional or professional) when supervising professionals in other disciplines. Complications can arise, for example, if a clinical social worker's supervisor is a physician or psychologist who follows their own state rules but is unaware of the same state's telehealth requirements for social work practice. It is, therefore, the clinical social worker's responsibility to be informed of and following the relevant standards, rules, and laws.

It should be noted that at the time of this writing, several bills are being considered in Congress that would provide national requirements for interstate clinical social work practice. Additionally, a compact template which would allow reciprocity across states is being developed with the guidance of Department of Defense, the Council of State Governments, the Clinical Social Work Association, the National Association of Social Work, the Association of Social Work Boards, and other stakeholders (CSWA, 2021). 


\section{Discussion}

The use of TBH is expanding due to increasing evidence that it provides ongoing access to services, especially during the COVID-19 pandemic, and that TBH services are both effective in treatment outcomes and cost (Hilty et al., 2018). Competencies are the integrative link between excellence in clinical practice, education, and technology; they are much needed in this era of service delivery and health care. Traditional training, evaluation, and faculty development can translate TBH research on clinical outcomes and models of care for generations to come. In turn, these well-trained and competent clinicians will leverage resources more efficiently and have the capacity to reach a wider range of populations, e.g., refugees across the world, rural areas, etc. Utilizing best practices from the fields of marriage and family therapy, psychiatry, psychology, addictions/substance use, social work, and other disciplines, if shared and integrated for competencies, will potentially strengthen this movement. With regard to clinical social work, the importance of ethical issues regarding confidentiality, informed consent, emergency services, attention to cultural diversity, legal considerations, and all other elements of the social work Code of Ethics (2017) must be integrated into TBH practice.

TBH competencies have a significant impact for the healthcare disciplines, their organizations/associations, and individual professionals. Traction most likely requires intra- and interprofessional interest, communication, and administration. It seems fitting for TBH competencies to be integrated into existing standards for professional conduct, practice and treatment guidelines, clinical care, and scopes of practice, which are set forth by professional organizations/associations and by professional licensing boards. The importance of educating clinical social work students, as well as current clinicians, in the use of TBH cannot be over-emphasized. Especially during this time of COVID, understanding the basic delivery of TBH services is as important as understanding how to diagnose and conduct psychotherapy (Wilkerson et al., 2020).

Ethical and effective TBH practice is also a call to action as it behooves LCSWs-whether practicing inperson or via TBH - to be fully aware of professional standards and evolving law. The NASW, ASWB, CSWE, \& CSWA Standards for Technology in Social Work Practice (2017) are an excellent guide for LCSWs using TBH. Much more input is needed from various stakeholders (Hilty et al., 2018), including clients/patients, family/ caregivers, professionals in healthcare, behavioral science, social science and technology, and leadership by professional organizations, such as CSWA and NASW, that represent clinical social work practice. Research and evaluation are necessary, regardless of the competency set, in order to evaluate the teaching/training and skill development by learners. It has been long established that data collection could include literature reviews, observations, surveys, focus groups, structured interviews, behavioral event interviews, and other logs (Marrelli et al., 2005). Finally, aside from all clinical stakeholders involved, it is not realistic to expect TBH competencies to be integrated into clinical practice without the involvement of major oversight stakeholders, including education and training programs, licensing boards, individual and organization certification and accreditation organizations, and professional organizations. Each plays a critical role in ongoing ethical and effective TBH clinical social work practice.

\section{Conclusion}

The CTiBS interprofessional TBH competencies framework can be a valuable guide for LCSWs who have begun using TBH service delivery for psychotherapy services. The special ethical and legal considerations for clinical social workers must be addressed by the state of the LCSW's licensure and the client/patient location, as well as by national standards. The inclusion of LCSWs as TBH clinicians wellversed in ethical and effective TBH practice will continue to provide greater access to mental health services-needed more than ever during the time of COVID-19 and beyond.

\section{Declarations}

Conflict of interest Laura W. Groshong is the Director of Policy and Practice, Clinical Social Work Association. The authors declare there are no other known conflicts of interest to disclose. Marlene M. Maheu is the Founder and Executive Director of the Telebehavioral Health Institute, which offers telehealth continuing education to social workers.

\section{References}

American Telemedicine Association. (2009). Practice guidelines for videoconferencing-based telemental health. http://www.ameri cantelemed.org/docs/default-source/standards/practice-guidelinesfor-videoconferencing-based-telemental-health.pdf?sfvrsn $=6$

American Telemedicine Association. (2013). ATA practice guidelines for video-based online mental health services. Telemedicine Journal and E-Health, 19(9), 722-730.

American Telemedicine Association. (2017). Practice guidelines for child and adolescent telemental health. Telemedicine Journal and E-Health. https://www.cdphp.com/-/media/files/providers/behav ioral-health/hedis-toolkit-and-bh-guidelines/practice-guidelinestelemental-health.pdf?la=en

Barsky, A. E. (2017). Social work practice and technology: Ethical issues and policy responses. Journal of Technology in Human Services, 35(1), 8. 
Camper, A. B. \& Felton, E. M. (2020). Telemental Health: Legal Considerations for Social Workers. https://www.socialwork ers.org/About/Legal/HIPAA-Help-For-Social-Workers/Telem ental-Health

Center for Connected Health Policy. Current state laws and reimbursement policies. https://www.cchpca.org/telehealth-policy/ current-state-laws-and-reimbursement-policies\#

Centers for Medicare and Medicaid Services. (2020). President Trump expands telehealth benefits for Medicare beneficiaries during COVID-19 outbreak. U.S. Department of Health and Human Services, National Institutes of Health. https://www. cms.gov/newsroom/press-releases/president-trump-expandstelehealth-benefits-medicare-beneficiaries-during-covid-19outbreak

Centers for Medicare and Medicaid Services. (2018). Information on Medicare telehealth. U.S. Department of Health and Human Services, National Institutes of Health. https://www.cms.gov/ About-CMS/Agency-Infor mation/OMH/Downloads/Infor mation-on-Medicare-Telehealth-Report.pdf

Clinical Social Work Association. (2021). CSWA-Legislative alert. DOD project to create LCSW reciprocity. https://www.clini calsocialworkassociation.org/Legislative-Alerts/10201784

Cwikel, J., \& Friedmann, E. (2019). E-therapy and social work practice: Benefits, barriers, and training. International Social Work, 10(1177), 0020872819847747.

Dreyfus, S. E., \& Dreyfus, H. L. (1980). A Five-Stage Model of the Mental Activities Involved in Directed Skill Acquisition. Storming Media.

Drude, K., Maheu, M., \& Hilty, D. (2019). Continuing professional development: Reflections on a lifelong learning process. Psychiatric Clinics of North America, 42(3), 447-461.

Hilty, D. M., Sunderji, N., Suo, S., Chan, S., \& McCarron, R. M. (2018). Telepsychiatry/telebehavioral health and integrated care: Evidence-based, best practice models and competencies. International Review of Psychiatry, 1, 1-18.

Hilty, D. M., Zalpuri, I., Torous, J., \& Nelson, E. L. (2020). Child and adolescent asynchronous technology competencies for clinical care and training: Scoping review. Family, Systems and Health, . https://doi.org/10.1037/fsh0000536

Iobst, W. F., Sherbino, J., Cate, T. O., Richardson, D. L., Dath, D., Swing, S. R., et al. (2010). Competency-based medical education in postgraduate medical education. Medical Teacher, 32(8), 651-656.

Levin, S., Fulginiti, A., \& Moore, B. (2018). The perceived effectiveness of online social work education: Insights from a national survey of social work educators. Social Work Education, 37(6), 775-789.

Maheu, M., Drude, K., Hertlein, K., Wall, K., Long, R., Luoma, T., \& Hilty, D. (2018). An interprofessional framework for telebehavioral competencies. Journal of Technology in Behavioral Science, 2(3-4), 190-210. https://doi.org/10.1007/ s42347-017-0038-y

Maheu, M., Pulier, M., Wilhelm, F., McMenamin, J., \& Brown-Connolly, N. (2005). The mental health professional and the new technologies: A handbook for practice today. Erlbaum.

Marrelli, A. F., Tondora, J., \& Hoge, M. A. (2005). Strategies for developing competency models. Administration and Policy in Mental Health, 32(5-6), 533-560.

McCarty, D., \& Clancy, C. (2002). Telehealth: Implications for social work practice. Social Work, 47(2), 153-161. https://doi. org/10.1093/sw/47.2.153

National Association of Social Workers. (2017). NASW code of ethics. https://www.socialworkers.org/About/Ethics/Code-of-Ethics/Code-of-Ethics-English

National Association of Social Workers, Association of Social Work Boards, Council on Social Work Education, \& Clinical Social
Work Association. (2017). NASW, ASWB, CSWE, \& CSWA standards for technology in social work practice. https://www. aswb.org/wp-content/uploads/2013/10/TechnologySWPractice. pdf

Northey, W. F., \& Gehart, D. R. (2019). The condensed MFT core competencies: A streamlined approach for measuring student and supervisee learning using the MFT core competencies. Journal of Marital and Family Therapy, 46(1), 42-61. https:// doi.org/10.1111/jmft.12386

Nelson, E. L., \& Sharp, S. (2016). A review of pediatric telemental health. Pediatric Clinics of North America, 63(5), 913-931. https://doi.org/10.1016/j.pcl.2016.06.011

Office for Civil Rights. (2020). Notification of enforcement discretion for telehealth remote communications during the COVID19 nationwide public health emergency. https://www.hhs.gov/ hipaa/for-professionals/special-topics/emergency-preparedness/ notification-enforcement-discretion-telehealth/index.html

Perron, B. E., Taylor, H. O., Glass, J. E., \& Margerum-Leys, J. (2010). Information and communication technologies in social work. Advances in Social Work, 11(2), 67-81.

Pickens, J. C., Morris, N., \& Johnson, D. (2019). The digital divide: Couple and family therapy programs' integration of teletherapy training and education. Journal of Marital and Family Therapy. https://doi.org/10.1111/jmft.12417

Wilkerson, D. A., Wolfe-Taylor, S. N., Deck, C. K., Wahler, E. A., \& Davis, T. S. (2020). Telebehavioral practice basics for social worker educators and clinicians responding to COVID19. Social Work Education. https://doi.org/10.1080/02615479. 2020.1807926

Wodarski, J., \& Frimpong, J. (2013). Application of e-therapy programs to social work practice. Journal of Human Behavior in the Social Environment, 23(1), 29. https://doi.org/10.1080/ 10911359.2013.737290

Publisher's Note Springer Nature remains neutral with regard to jurisdictional claims in published maps and institutional affiliations.

Crystal A. Merrill, PhD, LCSW-C is a Licensed Certified Social WorkerClinical in Maryland. Also licensed in FL and MN, she is a faculty member with Capella University's MSW program and maintains a private clinical practice. Specialties include families and children as well as technology in social work practice.

Marlene M. Maheu, PhD Telebehavioral Health Institute, Executive Director. Developed and delivered in-person and online telehealth training for more than 36,000 professionals from 94 countries. Cofounder of the Journal for Technology in Behavioral Science, author of $40+$ telehealth textbooks and journal articles, including CTIBS Framework for Telebehavioral Health Competencies.

Kenneth P. Drude, PhD is a psychologist in private practice near Dayton, Ohio, USA. He has actively participated in the development of state and national professional telebehavioral health guidelines and competencies and is the author and co-author of multiple psychology and telebehavioral health journal articles.

Laura W. Groshong, LICSW is a Licensed Independent Clinical Social Worker in Seattle, has worked clinical private practice for the past 43 years. She was co-editor for the Clinical Social Work Journal's "Technology in Clinical Social Work" edition and also Director of Policy and Practice for the Clinical Social Work Association. 
Mirean Coleman is a professional social worker who is a licensed mental health clinician and private practitioner. She has been instrumental in the development of technology standards and other technology products for social workers and has served on national technology committees including the Harvard School of Medicine Teletherapy Advisory Committee.
Donald M. Hilty, M.D. is a scholar in psychiatric and medical education, health services, and telemedicine. An international speaker and researcher, Dr. Hilty serves as Editor of both the Journal of Technology in Behavioral Science and Psychology and Cognitive Science. He is on the APA-IOM and APA-ATA Guideline Writing Groups. 